\title{
Correction to: Short Walk Adventures
}

\author{
Armin Straub and Wadim Zudilin
}

\section{Correction to:}

Chapter "Short Walk Adventures"

in: D. H. Bailey et al. (eds.), From Analysis to Visualization, Springer Proceedings in Mathematics \& Statistics 313, https://doi.org/10.1007/978-3-030-36568-4_27

The original version of Chapter "Short Walk Adventures" was inadvertently published with incorrect cross-citations in square brackets "[4] and $p_{2}(t)$ on [2]". This has now been amended correctly as on $[0,4]$ and $p_{2}(t)$ on $[0,2]$

$$
\begin{aligned}
& p_{2}\left(t^{1 / 2}\right) /\left(2 t^{1 / 2}\right) \text { on [4] and } p_{2}(t) \text { on [2], } \\
& \text { to } \\
& p_{2}\left(t^{1 / 2}\right) /\left(2 t^{1 / 2}\right) \text { on [0,4] and } p_{2}(t) \text { on [0,2], }
\end{aligned}
$$

The erratum chapter and the book have been updated with the change.

The updated version of the book can be found at

https://doi.org/10.1007/978-3-030-36568-4_27 